\title{
ON INVARIANCE EQUATION FOR MEANS OF POWER GROWTH
}

\section{ALFRED WitKOWSKI}

Abstract. We discuss properties of the solutions of the invariance equation

$$
M(N(x, y), K(x, y))=M(x, y)
$$

for homogeneous, symmetric means $M, N, K$ of power growth.

Mathematics subject classification (2010): 26E60.

Keywords and phrases: Mean, power growth, invariance equation.

\section{REFERENCES}

[1] Szabolcs BAJÁK, Invariance equation for Two-variable mean, $\mathrm{PhD}$ thesis, University of Debrecen, 2012.

[2] ÁdÁm BeSEnyeI, On the invariance equation for Heinz means, Math. Ineq. Appl., 16 (2013), 233 239.

[3] Jonathan M. Borwein And Peter B. Borwein, Pi and the AGM. A study in analytic number theory and computational complexity, Canadian Mathematical Society Series of Monographs and Advanced Texts. A Wiley-Interscience Publication. John Wiley \& Sons, Inc., New York, 1987. 